\title{
Research on Construction of Enterprise Informatization Based on Computer Application Technology
}

\author{
Jing Sun ${ }^{1, a}$ \\ ${ }^{1}$ China Petroleum Pipeline College, Langfang, Hebei, China \\ a731280003@qq.com
}

Keywords: Computer Application Technology, Enterprise informatization, Measures

\begin{abstract}
With the innovation of computer technology, computer application technology was used more widely in the enterprise. Computer application technology in the enterprise offers a variety of convenient services for enterprise production and management efficiency for different groups of people. In this paper, information technology enterprises not only can help companies better manage, but also improve their core competitiveness. Enterprise information refers to the use of computer technology to achieve business processes, material movement, transaction processing, cash flow, customer interaction and other business process automation. Business computer application technology and information technology an enterprise using computer technology, network technology and a series of modern technology, the depth of information resources through the development and widespread use, and constantly improve the production, operation, management, efficiency and level of decision-making, thereby enhancing economic efficiency and competitiveness of the process.
\end{abstract}

\section{Theoretical Introduction of Enterprise Informatization}

Enterprise Informatization is the business to business process (optimization) restructuring is based on a certain depth and breadth of the use of computer technology, network technology and database technology, all the information control and integrated management of production and operation activities, to achieve external enterprise sharing and effective use of information to improve economic efficiency and competitiveness in the market in a timely manner to provide accurate and effective data information and decision-making reference for business leaders.

Specific to an enterprise, information technology refers to electronics companies in the research, production, marketing and other aspects of a wide range of office using computer and network technology, enterprise production process automation of network management, decision support and business intelligence operations technology to reduce costs and expenses, increase production and sales, improve the economic efficiency of enterprises ${ }^{[1]}$.

Information technology is a process of advancing its development depends on three factors: First, the people on the deepening of understanding of their business activities, and second, the development of information technology, related to computing technology, network technology, artificial intelligence, etc. field; the third is on the business activities of IT penetration, the transformation ability and capacity that involves many technical systems. Enterprise information specific objectives are to optimize their business activities to make them more effective, its fundamental purpose is to improve the competitiveness of enterprises.

\section{Analysis of the Enterprise Information Network Construction}

After years of development, information technology infrastructure has tended to improve, the computer also gradually moving towards the business and the family, more and more business owners realize that the computer network technology to bring change, began to introduce computer network information in enterprise management technology, which provides a strong guarantee for China to promote information technology network. Although the overall situation tends to be good, but still want to see the shortcomings ${ }^{[2]}$.

At present, China's many logistics companies in the process of building a network of 
information and do not realize the importance of the site has its own business development, many companies will build a light on the top of the mouth with the hardware and management, and the quality of personnel is also relatively high, while ignoring the software side of the building and, in particular, a lot of companies do not have their own dedicated website, in recycling party information while still using the traditional methods. Some companies have been gradually recognized market practice information utilization importance for the development of enterprises, but also to start building your own website, but the site post-maintenance and management work is relatively backward, many sites often long after the completion without page and updated.

In fact, many companies building sites for the development of enterprises, it is not too practical, the site can't be delivered customer's ideas, but can't reflect the existence of the problem, they can't help enterprises grasp market trends, which is detrimental to the development of enterprises. Meanwhile, due to the lack of communication between the customers, they can't know the needs of customers, the stability of market channels naturally can't be guaranteed. In order to deal with unexpected situations timely discovery, causing the entire logistics enterprise information transmission system is still in its original level and did not give full play to the advantages of the network information construction ${ }^{[3]}$.

\section{The Significance of Enterprise Informatization Construction}

In the global knowledge-based economy and the rapid development of information technology today, information is the key factor in determining the success or failure, but also the business to achieve trans-regional, cross-ownership of an important prerequisite. The enterprise informatization construction can share resources, make use of modern information technology, research and development combined into one, effective development and utilization of information resources, seek to appropriate partners and projects to improve management, early out of the woods ${ }^{[4]}$. Fig. 1 shows the significance of enterprise informatization construction.

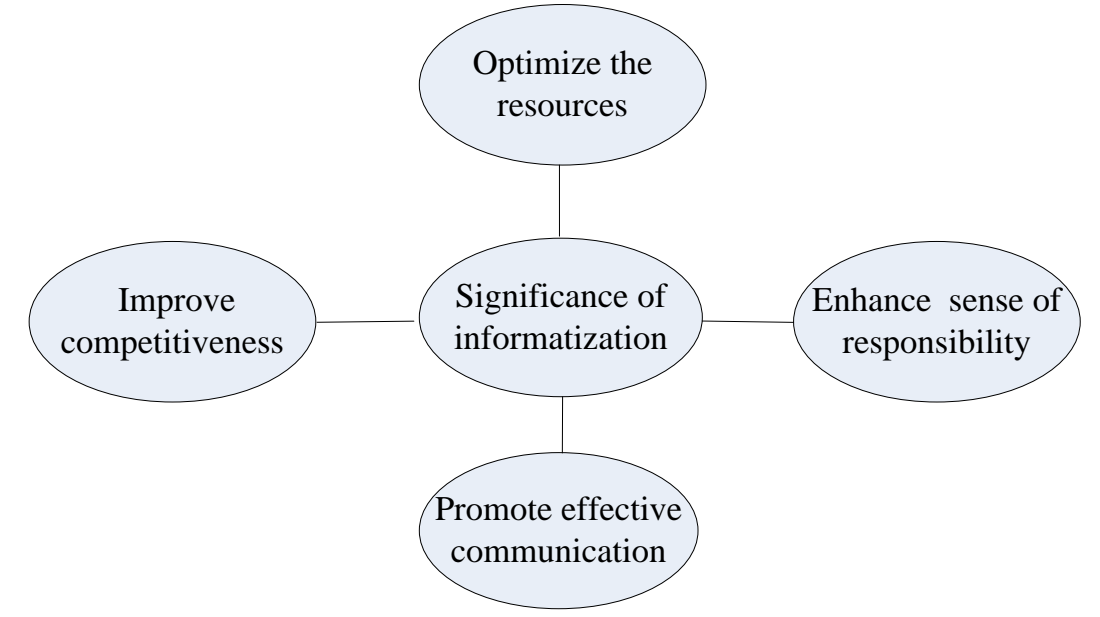

Fig. 1.The significance of enterprise informatization construction

Purpose computer application technology and information technology companies in order to give full play to the role of modern tools to provide more efficient and powerful support for enterprise development in order to improve overall core competitiveness, enterprise computer application technology and information technology for enterprises to timely grasp industry trends, market changes, which respond quickly to seize the opportunity to capture the market. Accelerate business process reengineering, organizational structure conducive to optimize, reduce costs and expand the scope of business competition, stimulate production, technological innovation, promote the progress of research and development projects to improve economic efficiency of enterprises to promote enterprise competition.

Business computer application technology and information technology to achieve clear responsibilities, clear job responsibilities and work to enhance people's sense of responsibility, reducing work Dodge, wrangling and other phenomena. Business computer application technology 
and information technology to achieve lower cost, greatly reduce office expenses, reduce management costs. Computer application technology has high speed, large capacity and other characteristics of the modern enterprise which can effectively guarantee the efficiency of enterprises, information technology can optimize the allocation of resources, improve enterprise management level, thereby enhancing the competitiveness of enterprises.

\section{The Enterprise Information Integration}

In order to solve the high-tech Enterprise Informatization integration problem, we have to find a practical way, that is, from the overall consideration of the enterprise information system, choose an appropriate integration platform, the enterprise organically integrate information silos, and businesses application Integration (EAI) is our best choice. EAI is the underlying structure by establishing contact across the entire heterogeneous enterprise systems, applications, data sources, etc. Figure 3 shown between the important internal systems. Fig.2 shows the EAI model design.

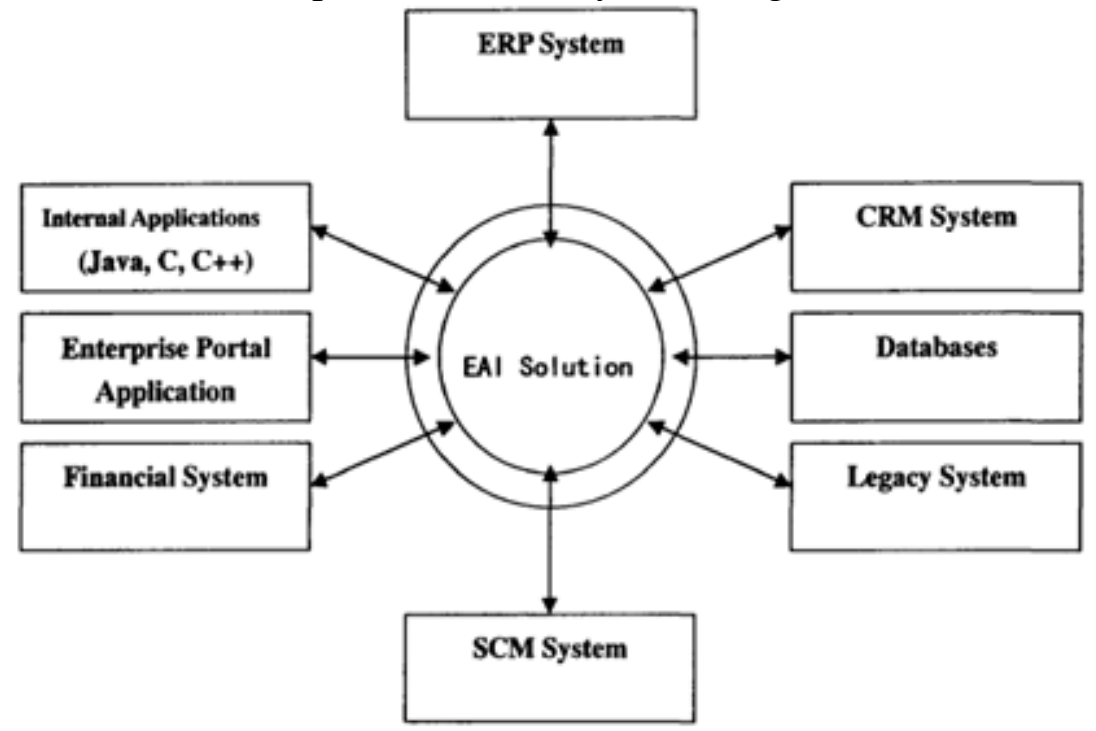

Fig. 2.The EAI model design

EAI is a new strategic business solution that leverage a common middleware (middleware) has been the integration of enterprise application software, packaged business applications as well as new code three functions. The integration refers to the integration of a user-oriented integration by providing a unified display interface to replace the original application system different graphical interfaces, thus hiding the background of different applications implementation details. Integrated logic interface as a conventional display integrated point to guide a user interactive operation, and communication between the operator and the corresponding software, and then the result produced by the different software components together, to avoid the user interface in different applications switching between, simplifying operations and improve efficiency.

Application integration requires integration points exist within the application code. Integrated Office may simply have to just use the open application programming interface to access, it may need to use additional code too complex segments to create a new access point. EAI business process integration is the most valuable part through the use of appropriate technology to standardize the information control, easy flow between input, output and transmission of information, sharing of information resources in different application systems business processes to optimize business overall business processes. Through the integration of business processes, can enable enterprises to enhance the sensitivity of the information, more quickly to market demand for information made to react and improve the competitiveness of enterprises.

\section{The Measures for the Enterprise Informatization Construction}

Chinese enterprises in the development process susceptible to the traditional concept of one-sided 
pursuit of economic efficiency of enterprises, while ignoring the enterprise management, enterprise management, the use of computer technology, enterprise information management, improve enterprise management level and economic, and computer information technology and information technology leadership in key decisions that affected the business concept of leadership, so we must change our philosophy of modern enterprise, the enterprise the production process, the use of computer technology and information technology to promote enterprise information management.

Enterprises must develop information technology personnel training programs, accelerate information personnel. Enterprises should believe talent, and give full play to the role of talent, so that they feel the importance of their business. Enterprises must strengthen the application of information technology and computer technology, computing technology is applied to various parts of the organization, a unified network system among various departments to facilitate the sharing of corporate resources, while helping enterprise informatization construction standards increase.

Enterprises in production and business activities, for computer application technology and information technology to conduct construction funds, only those with sufficient funds, some advanced computer applications software can get a better application of information technology in enterprises which, some advanced equipment in order to introduce the production and operation of enterprises which can guarantee the level of enterprise information management, thereby enhancing economic efficiency of enterprises, enhance competition in the market competitiveness.

\section{Conclusions}

With the economic globalization trend, the enterprise reform, reconstruction and modernization process would be tardigrade, the existence and development of enterprises would become a big problem without informatization. In this paper, the application of enterprise computer technology and information technology to make the relevant reports, in order to ensure the steady development of enterprises, enterprises must be familiar with the master of computer application technology, and increase training of professional and technical personnel, so as to promote the construction of enterprise information. Companies want to remain invincible in this environment, and use information technology reforms to reduce costs, increase efficiency, improve quality, thereby enhancing the international competitiveness of enterprises. According to the original enterprise information construction problems to be solved and business process analysis, an adaptation of business characteristics, integrated enterprise information model.

\section{References}

[1] E. J. Umbleetal. Enterprise resource planning: Implementation procedures and critical success factors [J].European Journal of Operational Research, 2005 (146):241-257.

[2] MANUELA SILVA, LUIZ MOUTINHO, ARNALDO COELHO, ALZIRAl MARQUES. Market orientation and performance: modelling a neural network [J].European Journal of Marketing Emerald Article, 2009, 43(3):421-437.

[3] Ing-Long $\mathrm{Wu}$, Jian-Liand Chen. A hybrid performance measure system for e-business investments in high-tech manufacturing: An empirical study. Information \& Management, 2006, 43, 364-377.

[4] Wei Guo, Ke Chen. An empirical study on improving the manufacturing informatization index system of China[J].Proceedings of the 1st international conference[C].Australian, ICST, 2008:1-6.

[5] John J. Morris. The Impact of Enterprise Resource Planning (ERP) Systems on the Effectiveness of Internal Controls over Financial Reporting. Journal of information systems 2011(2):129-133 